\title{
A Simplified Procedure for Base Sliding Evaluation of Concrete Gravity Dams under Seismic Action
}

\author{
M. Basili ${ }^{1}$ and C. Nuti ${ }^{2}$ \\ ${ }^{1}$ Department of Structural and Geotechnical Engineering, Sapienza University of Rome, Via A. Gramsci 53, Rome 00197, Italy \\ ${ }^{2}$ Department of Structural Engineering, University of "Roma Tre", Via C. Segre 4/6, Rome 00146, Italy
}

Correspondence should be addressed to M. Basili, michela.basili@uniroma1.it

Received 3 March 2011; Accepted 29 March 2011

Academic Editors: J.-F. Chen and H.-L. Luo

Copyright ( 2011 M. Basili and C. Nuti. This is an open access article distributed under the Creative Commons Attribution License, which permits unrestricted use, distribution, and reproduction in any medium, provided the original work is properly cited.

\begin{abstract}
Possible base sliding induced by an earthquake on concrete gravity dams is obtained by a simplified procedure. The model is a nonlinear single-degree-of-freedom system which takes into account dam-water-foundation interaction based on the model developed by Fenves and Chopra (1987). The nonlinearity is in the foundation rock, since a threshold value for the sliding foundation resistance, modeled with the Mohr-Coulomb yielding criterion including a frictional and a cohesive component, is imposed. Nonlinear step by dams is obtained by a simplified procedure. The model is a nonlinear single-degree-of-freedom system which takes into account dam-water-foundation interaction based on the model developed by Fenves and Chopra (1987). The nonlinearity is in the foundation rock, since a threshold value for the sliding foundation resistance, modeled with the MohrCoulomb yielding criterion including a frictional and a cohesive component, is imposed. Nonlinear step by step dynamic analyses are carried out on four case studies representing typical examples of Italian concrete gravity dams by utilizing several natural earthquakes. On the basis of the obtained results, a simplified methodology to estimate residual displacement without performing nonlinear dynamic analysis is presented. An example of application using as seismic input the elastic response spectra furnished by the Italian Code is also presented.
\end{abstract}

\section{Introduction}

Seismic safety evaluation of existing dams is required. Concrete gravity dams represent a relevant part of the 500 large dams existing in Italy. The existing dams were essentially built, within one century, in the early'60s. Seismic design was considered for few dams, those in the few areas where seismic action had to be examined. Design seismic forces were very small until recent times. According to the new forthcoming Italian Code for design, construction and retrofitting of dams, as well as design action, should be considered all over Italy except for Sardinia. In the light of these changes, it appears meaningful to have a method for a quick screening to verify seismic safety. It is expected that a considerable number of dams will be safe enough, though with some indications and prescriptions on water level, while more detailed analyses will be required for the remaining ones.
The question of base sliding has been explained in the literature by modeling the dam as a rigid block, for example, [1], or considering its flexibility, for example [2]. There are works which deepen the topic both analytically and experimentally [3]. The available examples are generally derived from particular case studies which refer to specific dams and seismic inputs, whereas no systematic studies on base sliding depending on dam characteristics, type of reservoir, and foundation rock are conduced. It is known that several factors must be considered in dam earthquake analysis [4]. It is straightforward that facing the problem in its complexity may be quite a difficult task. In fact, in case of very difficult models, problems are in general tackled one by one by facing the various aspects independently, as it happens, for example, for cracking propagation, dam-water interaction, and damfoundation-interaction, [5-9]. Only few works approach the problem with simple but complete models. In the literature, as examples, can be mentioned the works $[2,10,11]$ on 
earthquake-induced base sliding of concrete gravity dams by means of simplified models. Among them the one by Chopra and Zhang [10], where analytical procedures are developed considering hydrodynamic effects combined with seismic action to determine possible sliding of dam base is reported here for comparison purposes. The dam is modeled at first assuming it as a rigid block and then considering its flexibility. Structure-foundation interaction is not taken into account. The effect of different resistance values on base sliding is indirectly considered by assuming different friction coefficients. Due to its exploratory character, the investigation is carried out considering few earthquakes and by varying some parameters. The paper does not completely deepen the problem, since it does not involve all of its relevant aspects to come to general conclusions; moreover, the model considered is elastic and therefore it cannot take into account structure-foundation interaction.

For this reason, in order to obtain a first estimate of base sliding displacement, several seismic inputs are here considered and a simplified procedure is developed by using a nonlinear equivalent single-degree-of-freedom model which takes into account some of the most important factors influencing dam response (such as dam-water- foundation rock interaction). The method is described in detail in a previous paper [12]. It utilizes the model proposed by Fenves and Chopra [13] for simplified linear analysis, enriched to catch permanent base displacement by modeling the nonlinearity of the substructure, given a threshold value for the foundation sliding resistance fixed by Mohr-Coulomb yielding criterion, including a frictional and a cohesive component. On the basis of the aforementioned procedure, four dams, typical examples of the Italian stock, are analyzed under a set of natural earthquakes. Numerical results seem to allow a simplified procedure to give a first estimate of residual displacement as a function of seismic intensity, without performing nonlinear analysis just based on data fitting. Only basic information about the structure and the foundation rock is required. Such methodology could be applied for a preliminary assessment of seismic safety against base sliding of existing concrete gravity dams, given site elastic response spectrum, foundation rock type, and dam-reservoir characteristics. Several limit states, related to different probability levels of occurrence of the seismic event, are considered. Both cases of new and existing dams are examined, since seismic action is defined differently in these two instances.

\section{Mechanical Model}

The dynamic behavior of concrete gravity dams can be studied by means of an equivalent single-degree-of-freedom (SDOF) system which describes the fundamental mode response of the structure. The equivalent linear model with dam-water-foundation interaction proposed by Fenves and Chopra [13] is taken as starting point. The model is here enriched in order to compute residual displacement by modeling the nonlinearity of the substructure. It is presented in depth in [12], whereas only the main governing equations

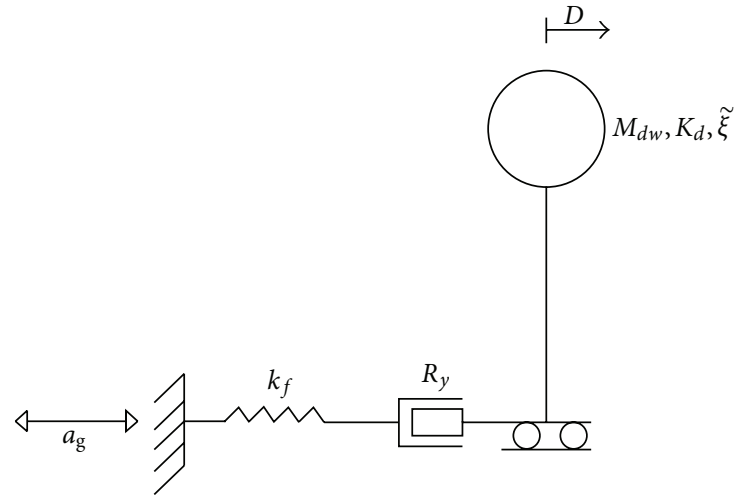

FIgURE 1: Equivalent SDOF nonlinear model.

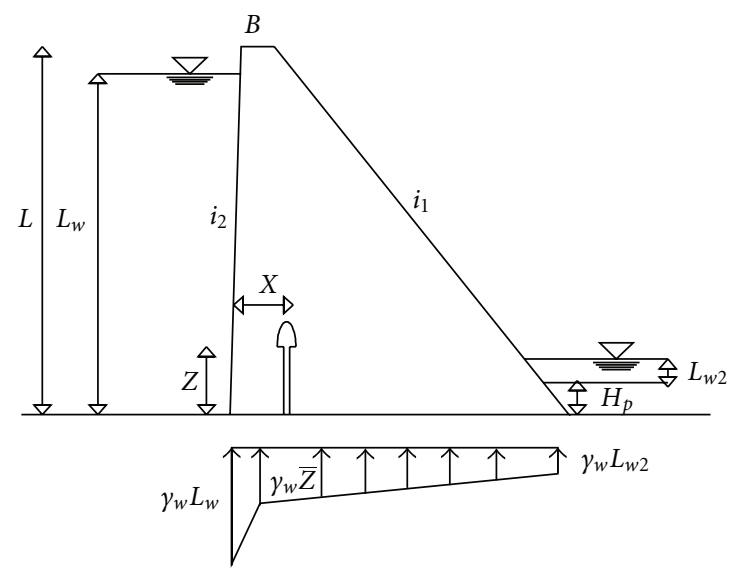

FIgURE 2: Uplift pressures on the dam basis and section geometry of the dam.

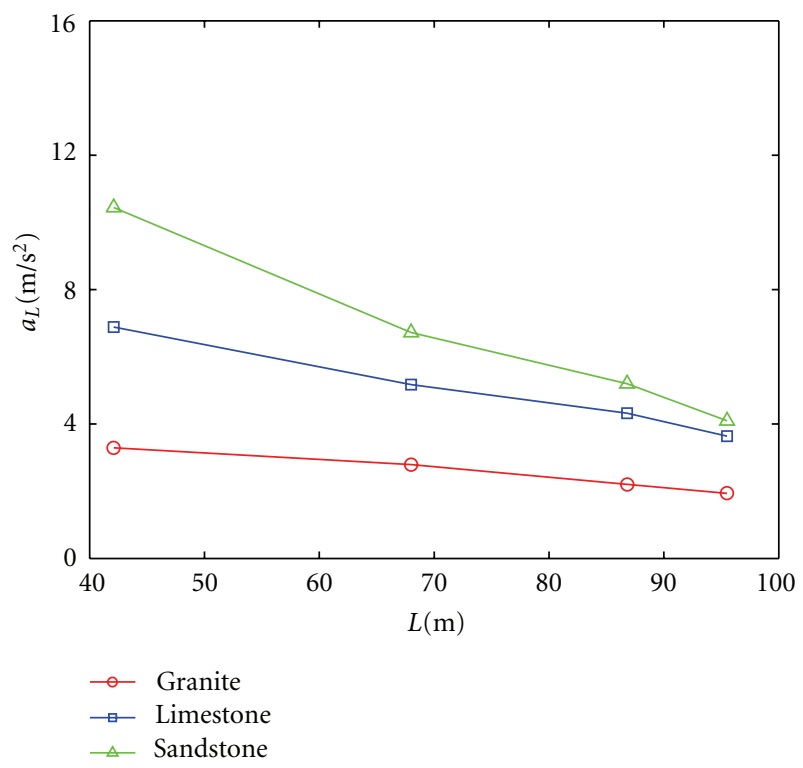

Figure 3: Normal flood reservoir case: behavior of limit acceleration versus dam height for different rock types. 


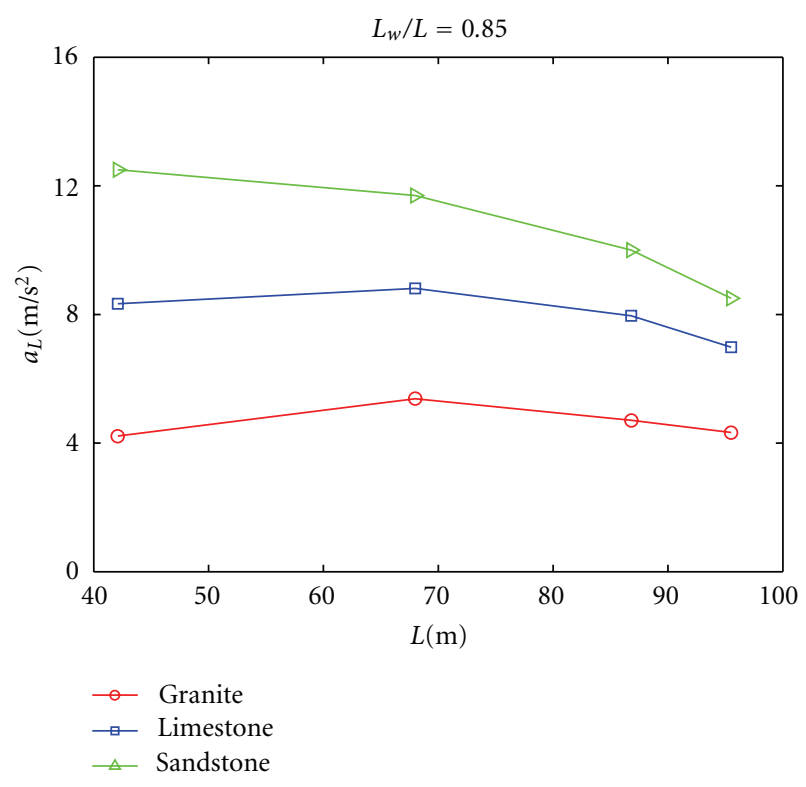

Figure 4: $L_{w} / L=0.85$ : behavior of limit acceleration versus dam height for different rock types.

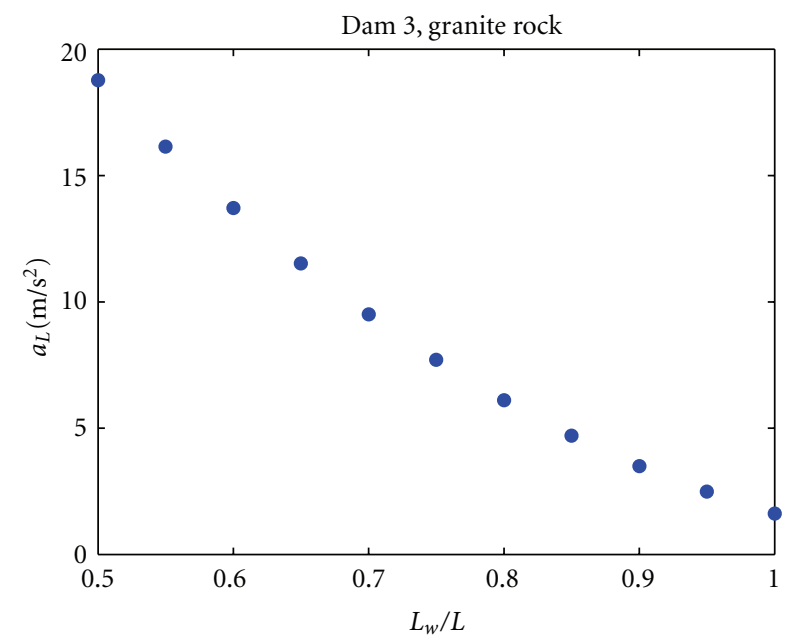

FIGURE 5: Development of limit acceleration versus water level to dam height ratio for Dam $3(L=86.8 \mathrm{~m})$ on granite rock.

are reported here and details on how to estimate model parameters can be found in [12].

The dam has the elastic Young's modulus $E(z)$, mass per unit of length $m(z)$, and height $L$. The response of a generalized single-degree-of-freedom system may be approximated as

$$
v(z, t)=\psi(z) y(t)
$$

Once having chosen the shape function $\psi(z)$, the amplitude of motion relative to the base is represented by the generalized coordinate $y(t)$. The assumed shape function represents the fundamental vibration mode shape for a standard dam

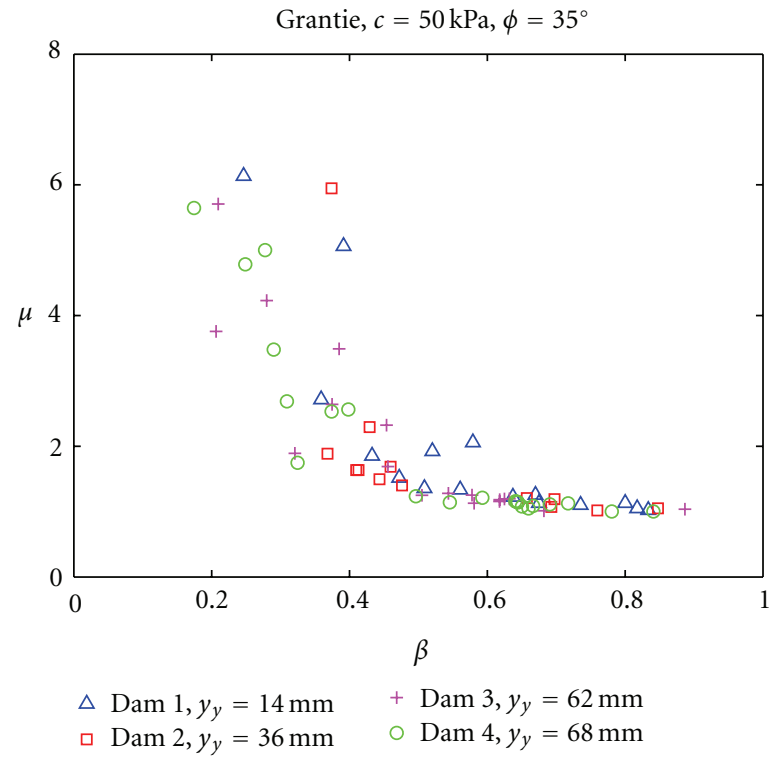

Figure 6: Foundation rock granite: ductility factor $\mu$ versus $\beta$ for the four dams.

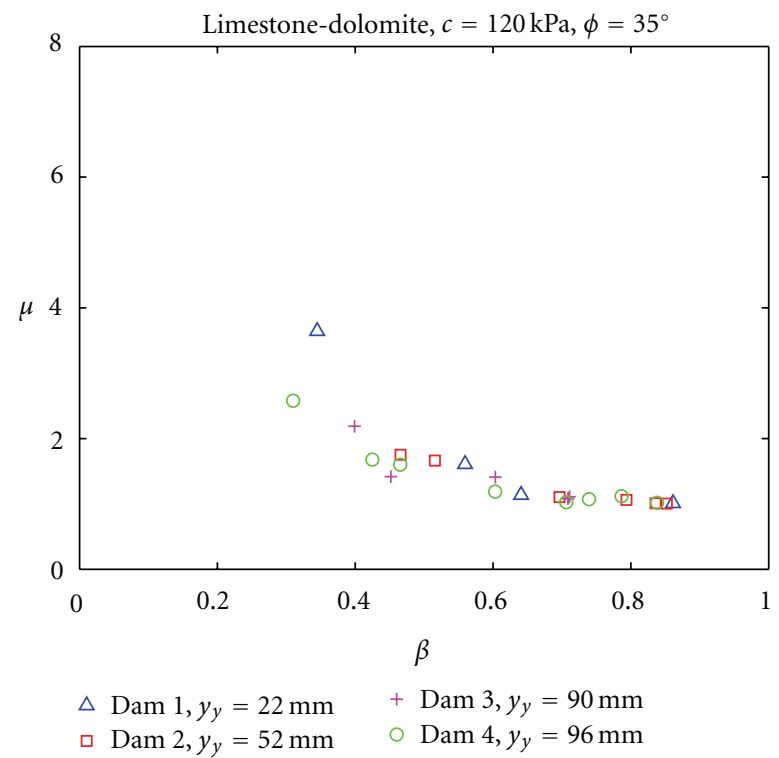

FIGURE 7: Foundation rock limestone-dolomite: ductility factor $\mu$ versus $\beta$ for the four dams.

cross section [13]. The shape function is normalized in order to assume the unity at the top of the dam $(\psi(L)=1)$; hence $y(t)$ represents dam top displacement.

The dynamic equilibrium of the equivalent linear SDOF system including dam-water-foundation interaction on a fixed base excited by horizontal earthquake ground motion represented by the base acceleration $a_{g}$ taken from [13] is here rearranged as

$$
M_{d w} \ddot{D}(t)+2 \tilde{\xi} \widetilde{\omega} M_{d w} \dot{D}(t)+\widetilde{\omega}^{2} M_{d w} D(t)=-M_{d w} a_{g}(t)
$$




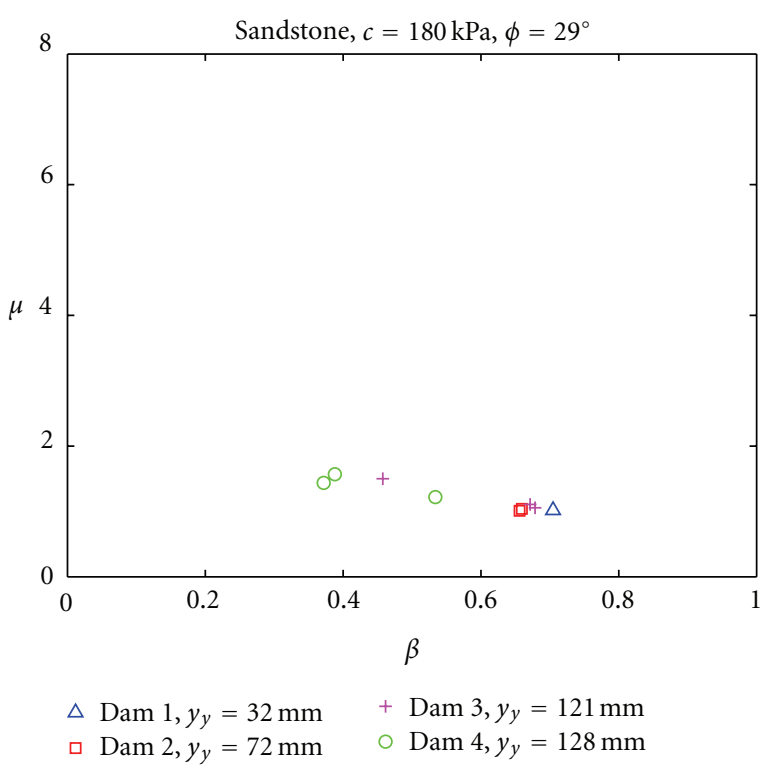

FIGURE 8: Foundation rock sandstone: ductility factor $\mu$ versus $\beta$ for the four dams.

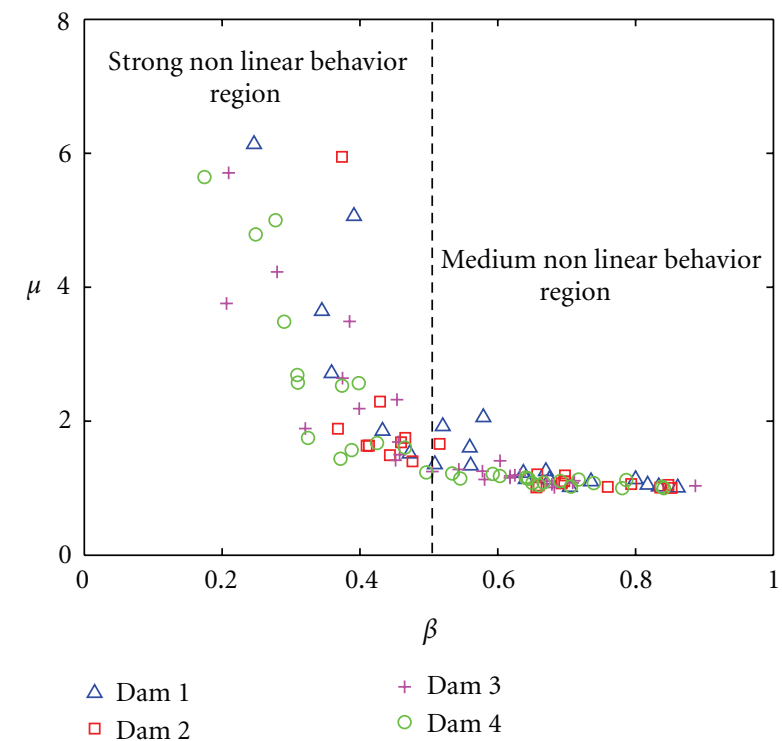

FIGURE 9: Ductility factor $\mu$ versus $\beta$ for the four dams.

where $D(t)=y(t) / p$, defining

$$
\begin{gathered}
p=\left(\frac{\widetilde{\omega}_{f}}{\omega}\right)^{2} \frac{\widetilde{L}}{\widetilde{M}}, \\
M_{d w}=\left(\frac{\widetilde{\omega}_{f}}{\omega}\right)^{2} \widetilde{L} .
\end{gathered}
$$

The solution of (2) gives dam response in terms of the relative displacement $D(t)$ of an equivalent SDOF system having the following dynamic characteristics:

$M_{d w}$ : equivalent SDOF system mass,

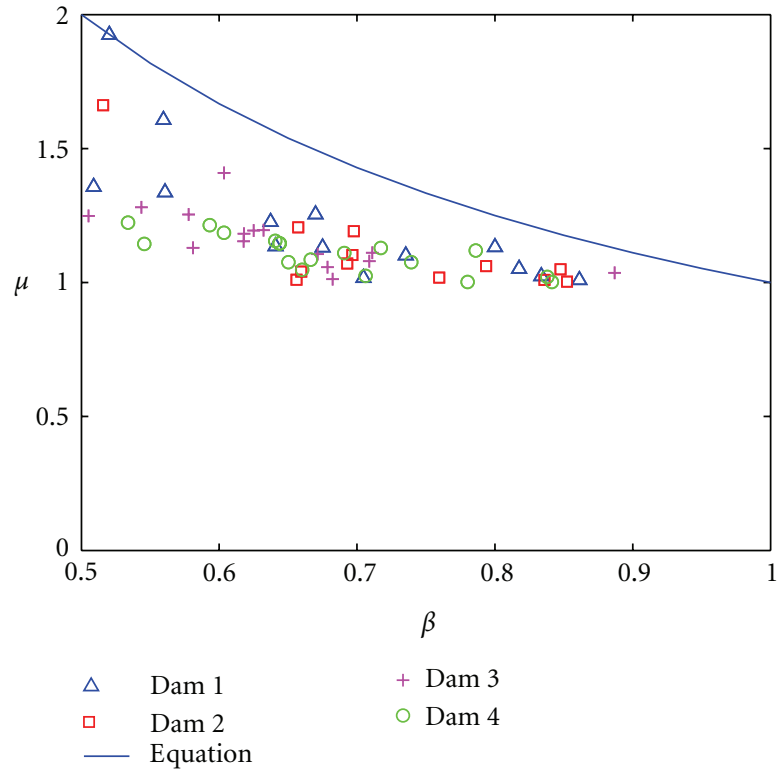

Figure 10: Ductility factor $\mu$ versus $\beta$ for the four dams, results are fitted by analytical expression in the range of $0.5<\beta<1$.

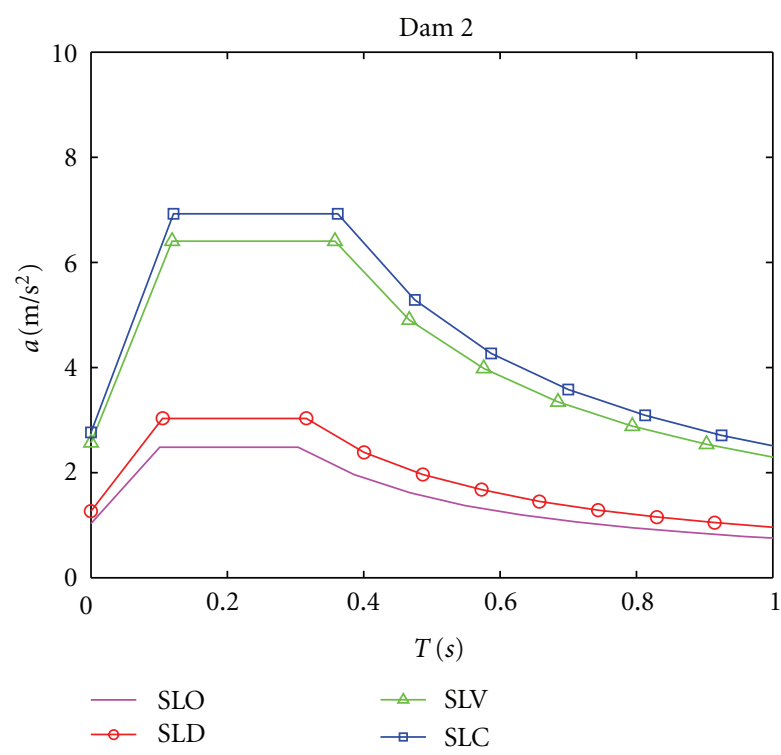

Figure 11: Italian Code, new dam: elastic response spectra for $\xi=$ $5 \%$ given by the Italian Code for the different limit states (SLO, SLD, SLV, SLC).

\section{$\widetilde{\xi}$ : equivalent SDOF system damping ratio, $\widetilde{\omega}$ : equivalent SDOF system natural frequency.}

Terms in (3), (4) are defined as

$\widetilde{M}=m^{*}+\operatorname{Re}\left(B_{1}\left(\omega_{r}\right)\right)=\int_{0}^{L} m(z) \psi(z)^{2} d z+$ $\operatorname{Re}\left(B_{1}\left(\omega_{r}\right)\right)$ which represents an equivalent mass, sum of two terms, one relative to dam and the other relative to water, 
$\widetilde{L}=\int_{0}^{L} m(z) \psi(z) d z+B_{0}\left(\omega_{r}\right)$ which represents an equivalent participation factor, sum of two terms, one relative to dam and the other relative to water,

$\omega$ equivalent SDOF system fundamental frequency without considering interaction with water or foundation rock,

$\widetilde{\omega}$ equivalent SDOF system fundamental frequency considering interaction with water and foundation rock,

$\tilde{\omega}_{f}$ equivalent SDOF system fundamental frequency considering interaction with foundation rock,

$\widetilde{\omega}_{r}$ equivalent SDOF system fundamental frequency considering interaction with water,

$\tilde{\xi}$ equivalent SDOF system damping ratio considering interaction with water and foundation rock.

$B_{0}$ and $B_{1}$ are hydrodynamic terms expressed as complex functions in the frequency domain.

In order to take into account the possibility of sliding of the dam on the foundation for evaluating residual displacement, the nonlinear constitutive behavior of dam-rock interface is modeled. A threshold value for the foundation sliding resistance is fixed, based on the Mohr-Coulomb yielding criterion which has both cohesive and frictional components. The resultant base sliding resistance depends on rock geotechnical parameters and on dam geometry, and it is expressed as the sum of a contribute due to cohesion $R_{y c}$ and a contribute due to friction $R_{y \phi}$ :

$$
R_{y}=R_{y c}+R_{y \phi}=c A+N \tan \phi,
$$

where $c$ is the cohesion, $\phi$ the friction angle, $A$ is the contact area, and $N$ is the force normal to the surface evaluated as

$$
N=P_{d}-U_{w}
$$

where $P_{d}$ is the dam weight and $U_{w}$ is the uplift pressure force resultant acting at the dam bottom.

When base shear force is lower than sliding foundation resistance $R_{y}$, the foundation behaves as elastic. As the base shear force equals the foundation resistance, plastic displacements arise and the energy input is dissipated at price of permanent deformations for the system attained at the end of the dynamic input. In the context of a simplified approach such behavior can be modeled with a monodimensional elastic-plastic constitutive law. The displacement of the foundation is

$$
D_{f}=\left\{\begin{array}{cc}
\frac{V_{b}}{k_{f}} & V_{b}<R_{y} \\
\frac{V_{b}}{k_{f}}+\forall & V_{b}=R_{y}
\end{array}\right\},
$$

where $V_{b}$ is the base shear force, $k_{f}$ is the elastic stiffness of the foundation rock, and $\forall$ means whichever value. The value selected for the elastic stiffness $k_{f}$ varies with the elastic modulus of the foundation rock $E_{f}$ and has been chosen by utilizing the curves reported in [14] which have been estimated for a shallow foundation on a homogeneous half space. In order to model the possibility of sliding between the dam and the foundation rock by means of an elastic plastic element, the equivalent SDOF system representing the dam is modeled as in Figure 1. The elastic stiffness of the equivalent SDOF system $K=\widetilde{\omega}^{2} M_{d w}$ (where $\tilde{\omega}$ has been previously defined and $M_{d w}$ is estimated as in (4)) is rearranged into two terms which work as elements in series. The first term is the elastic stiffness of the foundation rock $k_{f}$ and the second term is consequently evaluated as

$$
K_{d}=-\frac{K k_{f}}{K-k_{f}} .
$$

In conclusion, the parameters to be estimated considering dam-water-foundation interaction with the possibility of sliding are summarized in Figure 1:

(i) $M_{d w}, K_{d}, \tilde{\xi}, k_{f}, R_{y}, p$

To estimate the system's dynamic characteristics, simplified expressions proposed in [13] are used. The expressions obtained in order to estimate mechanical parameters of the equivalent SDOF nonlinear model (Figure 1) are furnished in [12]. The relationship between the forces acting on the equivalent SDOF system and the forces acting on the dam is explained in detail in [12] and follows the now popular procedure utilized in push-over analysis for the reduction of a multi-DOF system into a generalized SDOF system. As a result, dam base shear force is obtained by multiplying SDOF system base shear force by the coefficient $p$. Therefore, when performing the analysis on the generalized SDOF system, each force term $R_{i}$ must be inserted by dividing the value of the action by the $p$ coefficient.

\section{Actions Model}

Forces acting on the dam can be divided into static and dynamic ones. The static forces considered in the analysis are

$P_{d}$ : dam weight,

$P_{w}$ : horizontal hydrostatic force,

$U_{w}$ : resultant uplift pressure force,

$R_{p}$ : contribution of a passive wedge resistance, when applicable.

Each force is computed considering the planar problem having the shape of a transverse vertical section of the dam with a unit depth.

The horizontal hydrostatic force is computed as

$$
P_{w}=\frac{1}{2} \gamma_{w} L_{w}^{2}
$$

where $\gamma_{w}$ is the water density and $L_{w}$ is the water level in the reservoir. In the simplified model, such force is applied to the SDOF system.

The parameters to be considered to compute the resultant uplift pressure force, $U_{w}$, are the water level in the reservoir $\left(L_{w}\right)$, the position of the drain towards the 
TABLE 1: Earthquake data from Italian Earthquake strong motion database, PEER, and ESD database. Station name, earthquake, date, magnitude, epicentral distance, file name, horizontal peak ground acceleration.

\begin{tabular}{|c|c|c|c|c|c|c|}
\hline Station & Earthquake & Date & $\mathrm{Mw}$ & Ep.D. $(\mathrm{km})$ & Name & HPGA $(\mathrm{g})$ \\
\hline Assisi-Stallone & Umbria Marche & $26 / 09 / 1997$ & 6 & 21 & A-AAL018 & 0.19 \\
\hline Nocera Umbra-Biscontini & Umbria Marche & 06/10/1997 & 5.5 & 10 & E-NCB000 & 0.26 \\
\hline Nocera Umbra 2 & Umbria Marche & 03/04/1998 & 5.1 & 10 & R-NC2000 & 0.38 \\
\hline Tolmezzo-Diga Ambiesta & Friuli & $06 / 05 / 1976$ & 6.5 & 23 & A-TMZ000 & 0.36 \\
\hline Borgo-Cerreto Torre & Umbria Marche & $26 / 09 / 1997$ & 6 & 25 & A-BCT000 & 0.07 \\
\hline Tarcento & Friuli & $11 / 09 / 1976$ & 5.3 & 8 & TRT000 & 0.21 \\
\hline Borgo-Cerreto Torre & Umbria Marche & $14 / 10 / 1997$ & 5.6 & 12 & J-BCT000 & 0.34 \\
\hline Nocera Umbra 2 & Umbria Marche & 05/04/1998 & 4.8 & 10 & S-NC2000 & 0.17 \\
\hline Borgo-Cerreto Torre & Umbria Marche & $12 / 10 / 1997$ & 5.2 & 11 & I-BCT000 & 0.17 \\
\hline Assisi-Stallone & Umbria Marche & 06/10/1997 & 5.5 & 20 & E-AAL018 & 0.10 \\
\hline Borgo-Cerreto Torre & Umbria Marche & 26/09/1997 & 5.7 & 23 & В-ВСТ000 & 0.18 \\
\hline San Rocco & Friuli & $15 / 09 / 1976$ & 6 & 17 & B-SRO000 & 0.06 \\
\hline Nocera Umbra-Biscontini & Umbria Marche & 03/10/1997 & 5.3 & 8 & C-NCB000 & 0.19 \\
\hline Tolmezzo-Diga Ambiesta & Friuli & $07 / 05 / 1976$ & 5.2 & 27 & C-TMZ000 & 0.12 \\
\hline Nocera Umbra-Biscontini & Umbria Marche & 07/10/1997 & 4.2 & 10 & F-NCB000 & 0.05 \\
\hline Nocera Umbra-Biscontini & Umbria Marche & 07/10/1997 & 4.5 & 10 & G-NCB000 & 0.07 \\
\hline Nocera Umbra-Biscontini & Umbria Marche & $11 / 10 / 1997$ & 4.3 & 14 & H-NCB000 & 0.09 \\
\hline Cascia & Umbria Marche & $14 / 10 / 1997$ & 5.6 & 23 & $\mathrm{~J}-\mathrm{CSC} 000$ & 0.05 \\
\hline San Rocco & Friuli & $11 / 09 / 1976$ & 5.3 & 15 & SR-ONS & 0.03 \\
\hline San Rocco & Friuli & $11 / 09 / 1976$ & 5.5 & 17 & W-SRO000 & 0.09 \\
\hline Nocera Umbra 2 & Central Italy & 05/04/1998 & 4.8 & 10 & S-NC2090 & 0.15 \\
\hline Nocera Umbra 2 & Central Italy & 03/04/1998 & 5.1 & 10 & R-NC2090 & 0.31 \\
\hline Nocera Umbra-Biscontini & Central Italy & $14 / 10 / 1997$ & 5.6 & 23 & J-NCB090 & 0.05 \\
\hline Assisi-Stallone & Central Italy & 26/09/1997 & 5.7 & 24 & B-AAL108 & 0.15 \\
\hline Borgo-Cerreto Torre & Central Italy & 26/09/1997 & 6 & 25 & A-ВСТ090 & 0.11 \\
\hline Auletta & Campano Lucano & $23 / 11 / 1980$ & 6.9 & 25 & Auletta-NS & 0.06 \\
\hline Torre del Greco & Campano Lucano & $23 / 11 / 1980$ & 6.9 & 80 & Torre-NS & 0.06 \\
\hline Bagnoli-Irpino & Campano Lucano & $23 / 11 / 1980$ & 6.9 & 23 & Bagnoli-NS & 0.13 \\
\hline Villetta Barrea & Lazio Abruzzo & $11 / 05 / 1984$ & 5.5 & 6 & A-VLB000 & 0.15 \\
\hline Milazzo & Basso Tirreno & $15 / 04 / 1978$ & 6 & 34 & MLZ000 & 0.07 \\
\hline Ponte Corvo & Lazio Abruzzo & 07/05/1984 & 5.9 & 22 & PON-NS & 0.06 \\
\hline Lazio Abruzzo & Southern Italy & 07/05/1984 & 5.9 & 5 & ATI-WE & 0.12 \\
\hline Lazio Abruzzo & Southern Italy & $11 / 05 / 1984$ & 4.8 & 8 & D-VLB000 & 0.15 \\
\hline Gubbio & Central Italy & $29 / 04 / 1984$ & 5.6 & 17 & I-GBB090 & 0.07 \\
\hline Sortino & Sicily, Italy & $13 / 12 / 1990$ & 5.6 & 29 & SRT270 & 0.11 \\
\hline Sturno & Campano Lucano & $23 / 11 / 1980$ & 6.9 & 32 & Sturno-NS & 0.23 \\
\hline Loma Prieta & California & $18 / 101989$ & 6.9 & 28.6 & LOMAP & 0.473 \\
\hline Kocaeli & Turkey & $17 / 08 / 1999$ & 7.4 & 5.3 & IZMIT & 0.152 \\
\hline Kocaeli & Turkey & 17/08/1999 & 7.4 & 47 & GBZ000 & 0.244 \\
\hline Chi-Chi & Taiwan & 20/09/1999 & 7.6 & 152.7 & TAP051 & 0.112 \\
\hline N. Palm Springs & California & 08/07/1986 & 6 & 46.2 & ARM360 & 0.129 \\
\hline Bucarest & Romania & 04/03/1977 & 7.5 & 4 & Bucarest & 0.194 \\
\hline Dayhook & Iran & 06/09/1978 & 7.4 & 11 & Dayhook & 0.385 \\
\hline Montenegro & Montenegro & $15 / 04 / 1979$ & 6.9 & 65 & Montenegro & 0.256 \\
\hline Kozani & Grecia & $13 / 05 / 1995$ & 6.5 & 7 & Kozani & 0.208 \\
\hline Sakarya & Turkey & 17/08/1999 & 7.6 & 34 & Sakarya & 0.361 \\
\hline Ulcinj & Montenegro & $15 / 04 / 1979$ & 6.9 & 21 & Ulcinj & 0.224 \\
\hline
\end{tabular}


TABLE 2: Dams cases of study: construction year and section geometry, see Figure 2.

\begin{tabular}{lcccccccccc}
\hline Dam tag & $L(\mathrm{~m})$ & $B$ & $i_{1}(\mathrm{~m})$ & $i_{2}$ & $L_{w}(\mathrm{~m})$ & $L_{w 2}(\mathrm{~m})$ & $X(\mathrm{~m})$ & $Z$ & $H_{p}$ & $L_{w} / L$ \\
\hline 1 & 42.1 & 4 & 0.74 & 0 & 37.5 & 3.25 & 2.75 & 3.25 & 2.5 & 0.89 \\
2 & 68 & 0 & 0.73 & 0.2 & 66 & 6 & 9.1 & 6 & 3.6 & 0.97 \\
3 & 86.8 & 5 & 0.7 & 0 & 83.8 & 15 & 2.8 & 3.5 & 15 & 0.97 \\
4 & 95.5 & 0 & 0.8 & 0 & 92.5 & 4.5 & 4.25 & 11.5 & 9 & 0.97 \\
\hline
\end{tabular}

TABLE 3: Mechanical and geotechnical parameters for the different foundation rock types.

\begin{tabular}{lccc}
\hline Rock type & $\begin{array}{c}\text { Mechanical } \\
\text { parameter } \\
E_{f}\left(\mathrm{kN} / \mathrm{m}^{2}\right)\end{array}$ & \multicolumn{2}{c}{ Geotechnical parameters } \\
\hline Granite & $60010^{5}$ & 50 & $\Phi 5^{\circ}$ \\
Limestone-dolomite & $40010^{5}$ & 120 & $35^{\circ}$ \\
Sandstone & $20010^{5}$ & 180 & $29^{\circ}$ \\
\hline
\end{tabular}

upstream face $(X)$, the drain effectiveness $(\eta)$, the elevation of the drainage tunnel $(Z)$, and the eventual presence of water downstream $\left(L_{w 2}\right)$. On the whole, one evaluates the effectiveness of the drainage system by increasing water level in correspondence of the drainage tunnel with respect to drainage level by the quantity $\bar{Z}$ :

$$
\bar{Z}=f\left(\eta, L_{w}, Z, L_{w 2}\right) \geq Z \text {. }
$$

Depending on the dam geometry, the resultant force is then calculated by integrating the uplift pressure on the dam basis, Figure 2. According to the Italian Code, a constraint on the maximum uplift pressure on the line of the drainage system is imposed. In fact, since it corresponds to the drainage tunnel position, the maximum hydrostatic pressure should not be considered lower than

$$
\gamma_{w} \bar{Z}=\gamma_{w}\left[L_{w 2}+0.35\left(L_{w}-L_{w 2}\right)\right] .
$$

In the present model, such force acts reducing the sliding foundation resistance, (6).

The contribution of a passive wedge resistance to the sliding resistance of the dam is considered. The resultant force obtained from the distribution of the passive resistance stress $\sigma_{h p}$ at the base of the dam, downstream is

$$
R_{p}=\int_{0}^{H_{p}} \sigma_{h p} d z
$$

where $H_{p}$ is the height of the embedment. The assumed hypotheses to calculate the passive resistance are

(1) the force mobilizes instantaneously without needing residual displacement,

(2) the geotechnical parameters refer to the rock of the base foundation; however, to take into account superficial fracture, the residual values are utilized,

(3) the effect of the interstitial water is not taken into account in computing the vertical stress of the embedment.
The passive resistance stress $\sigma_{h p}$ is evaluated as

$$
\sigma_{h p}=2 c \sqrt{K_{p}}+\sigma_{v} K_{p},
$$

where $c$ is the cohesion, $\sigma_{v}$ is the vertical tension induced by the embedment, and $K_{p}$ is

$$
K_{p}=\frac{1+\operatorname{sen} \phi}{1-\operatorname{sen} \phi}
$$

with $\phi$ being the friction angle. Since for the hypothesis 1. the passive resistance mobilizes as the plastic threshold of the foundation rock is reached, one can state that this contribution induces an increase of the resulting sliding foundation resistance. As a result, the threshold value of the resultant sliding resistance $\widetilde{R}_{y}$ is

$$
\widetilde{R}_{y}=R_{y}+R_{p} .
$$

Seismic inputs are represented by earthquake records from available data banks. Records are taken from the Italian Earthquake strong motion database [15] which refers to seismic events happened in Italy over the period from 1972 to 1998. Data mainly refer to medium intensity seismic events (magnitude 4.5-6), while only few pertain to strong intensity events (magnitude 6-7). For this reason, in order to obtain general results that are valid also in the range of strong intensities, other recordings referring to very severe events have been taken from the Pacific Earthquake Engineering Research Center, PEER [16], and from the European Strong Motion Database, ESD [17]. To perform the analysis, signals referred to soil type A (rock) have been used the usual soil for concrete gravity dams. The list of the acceleration time histories used is reported in Table 1 for the Italian, PEER, and ESD earthquakes, where for each event the following data are given: station name, earthquake, date, magnitude, epicentral distance, file name, and horizontal peak ground acceleration. In total, 47 natural earthquakes have been used for the analysis.

\section{Case Studies}

4.1. Structural Model and Foundation Rock. Seismic response analysis is carried out on four typical examples of Italian concrete gravity dams. The four dams differ for height and geometry. The height range examined is representative of the interval of low-medium-high Italian dams.

The main characteristics of the dams analyzed are reported in Table 2, where each parameter is defined in 
TABLE 4: Mechanical parameters of the equivalent SDOF system for the four dams and the three foundation rock types considered.

\begin{tabular}{llccccccc}
\hline Dam tag & Rock type & $M_{d w}($ ton $)$ & $K_{d}(\mathrm{kN} / \mathrm{m})$ & $\tilde{T}(\mathrm{~s})$ & $\tilde{\xi} \%$ & $k_{f}(\mathrm{kN} / \mathrm{m})$ & $\widetilde{R}_{y}(\mathrm{kN})$ & $p$ \\
\hline \multirow{3}{*}{1} & Granite & 356.67 & $8.2910^{5}$ & 0.13 & 7 & $20310^{5}$ & 3124.6 & 3.54 \\
& Limestone-dolomite & 320.29 & $6.7110^{5}$ & 0.14 & 8 & $15010^{5}$ & 4378.5 & 3.17 \\
& Sandstone & 266.47 & $4.710^{5}$ & 0.15 & 11 & $82.510^{5}$ & 5394.1 & 2.64 \\
\hline \multirow{3}{*}{2} & Granite & 1237.4 & $9.3810^{5}$ & 0.23 & 7 & $20310^{5}$ & 10200 & 3.17 \\
& Limestone-dolomite & 1111.2 & $7.610^{5}$ & 0.25 & 8 & $15010^{5}$ & 13254 & 2.84 \\
& Sandstone & 924.45 & $5.3310^{5}$ & 0.27 & 11 & $82.510^{5}$ & 15238 & 2.37 \\
\hline \multirow{3}{*}{3} & Granite & 1748.5 & $8.1810^{5}$ & 0.3 & 7 & $20310^{5}$ & 13177 & 3.69 \\
& Limestone-dolomite & 1570.1 & $6.6210^{5}$ & 0.31 & 8 & $15010^{5}$ & 17173 & 3.32 \\
& Sandstone & 1306.3 & $4.6410^{5}$ & 0.34 & 11 & $82.510^{5}$ & 19276 & 2.76 \\
\hline \multirow{3}{*}{4} & Granite & 2262 & $8.7110^{5}$ & 0.33 & 7 & $20310^{5}$ & 16613 & 3.43 \\
& Limestone-dolomite & 2031.2 & $7.0510^{5}$ & 0.35 & 8 & $15010^{5}$ & 21023 & 3.08 \\
& Sandstone & 1689.9 & $4.9410^{5}$ & 0.38 & 11 & $82.510^{5}$ & 23297 & 2.57 \\
\hline
\end{tabular}

TABLE 5: Return period ( $\left.T_{\mathrm{RET}}\right)$-in years-for the different limit states considered, relative to the probability of exceeding $P_{V R}$ for new $\left(V_{R}=200\right)$ and existing dams $\left(V_{R}=100\right)$.

\begin{tabular}{lccc}
\hline Limit state & $P_{V R} \%$ & $T_{\text {RET }}$ new & $T_{\text {RET }}$ existing \\
\hline SLO & 81 & 120 & 60 \\
SLD & 63 & 200 & 100 \\
SLV & 10 & 1900 & 950 \\
SLC & 5 & 2475 & 1946 \\
\hline
\end{tabular}

TABLE 6: Peak ground acceleration for each dam for an action having a return period $T_{\mathrm{RET}}=475$ years.

\begin{tabular}{lcc}
\hline Dam tag & $L(\mathrm{~m})$ & $a_{g}$ \\
\hline 2 & 68 & $0.173 g$ \\
3 & 86.8 & $0.15 g$ \\
4 & 95.5 & $0.196 g$ \\
\hline
\end{tabular}

Figure 2. The Young's modulus is assumed to be $E=$ $241.2910^{5} \mathrm{kN} / \mathrm{m}^{2}$, whereas the structural damping ratio is assumed to be $\xi=5 \%$.

In order to get the influence of different foundation, three types of rocks have been considered: granite, limestonedolomite, and sandstone. The geotechnical parameters are reported in Table 3. Such values refer to real data which are relative to typical foundation rocks.

The mechanical parameters obtained for the equivalent SDOF system are summarized in Table $4 . M_{d w}, K_{d}, \widetilde{T}, \widetilde{\xi}$ represent the mechanical parameters of the dam considered with water and foundation rock interaction, estimated by applying (4) and (7) for $M_{d w}$ and $K_{d}$, respectively, and expressions furnished in [12] for $\widetilde{T}$ and $\widetilde{\xi}, k_{f}$ and $\widetilde{R}_{y}$ represent the geotechnical characteristics estimated with (15) for $\widetilde{R}_{y}$ and with curves reported in [14] for $k_{f}$. Finally, $p$ is the seismic input participation factor estimated by applying (3). These parameters are opportunely estimated in order to agree with the one degree of freedom model utilized for the dynamic analysis.
To present the results of the dynamic analyses some response quantities are defined. Attention is focused on the resultant sliding resistance $\widetilde{R}_{y}$ representing a static quantity, and on the limit acceleration $a_{L}$, representing a dynamic quantity, here defined as the limit response acceleration, which, when overtaken, produces sliding of the dam:

$$
a_{L}=\frac{\widetilde{R}_{y}-P_{w}}{M_{d w}},
$$

where $\widetilde{R}_{y}$ is the resultant sliding resistance, $P_{w}$ is the water pressure static resultant (9), and $M_{d w}$ is the equivalent mass of the SDOF system (4). The acceleration ratio $\beta$ :

$$
\beta=\frac{a_{L}}{a(\tilde{T})},
$$

where $a_{L}$ is the limit response acceleration (16), and $a(\tilde{T})$ representing the spectral acceleration evaluated at the period $\widetilde{T}$ from the acceleration response spectra of the seismic action with a conventional damping ratio $\xi=5 \%$ is the input intensity measure. When $\beta$ is greater than unity, the sliding foundation resistance is greater than the shear force developed by the seismic action and the structural system remains in the elastic field. Contrawise, when $\beta$ is lower than the unity, the system exhibits nonlinear response and plastic displacement occurs. For each dam and foundation rock, it is possible to estimate a priori the value of $a_{L}$ and for each accelerogram the corresponding $\beta$ is obtained. Shome et al. [18] have shown that $\beta$ is a good scaling parameter for nonlinear response. As output measure, the ratio between maximum displacement at dam top and dam top displacement when maximum sliding resistance is reached-here named ductility factor $\mu$-is utilized:

$$
\mu=\frac{D_{\max }}{D_{y}}=\frac{y_{\max }}{y_{y}},
$$

where $D_{\max }$ and $D_{y}$ are, respectively, the maximum displacement and the yielding displacement of the equivalent SDOF system, whereas $y_{\max }$ and $y_{y}$ are, respectively, the maximum 
TABLe 7: New dams: spectral acceleration given by the Italian Code for the different limit states (SLO, SLD, SLV, SLC) and for an action with return period of $T_{\mathrm{RET}}=475$ years, for granite.

\begin{tabular}{lccccccc}
\hline Dam & Period $(\mathrm{s})$ & Rock type & SLO $a(\widetilde{T})\left(\mathrm{m} / \mathrm{s}^{2}\right)$ & $\operatorname{SLD} a(\widetilde{T})\left(\mathrm{m} / \mathrm{s}^{2}\right)$ & $\operatorname{SLV} a(\widetilde{T})\left(\mathrm{m} / \mathrm{s}^{2}\right)$ & $\operatorname{SLC} a(\widetilde{T})\left(\mathrm{m} / \mathrm{s}^{2}\right)$ & $\mathrm{SL}_{475} a(\widetilde{T})\left(\mathrm{m} / \mathrm{s}^{2}\right)$ \\
\hline 2 & 0.23 & granite & 2.49 & 3.03 & 6.41 & 6.93 & 4.14 \\
3 & 0.3 & & 1.85 & 2.4 & 6.06 & 6.67 & 3.58 \\
4 & 0.33 & & 2.2 & 3 & 7 & 7.85 & 4.17 \\
\hline
\end{tabular}

TABLE 8: Existing dams: spectral acceleration given by the Italian Code for the different limit states (SLO, SLD, SLV, SLC) for granite.

\begin{tabular}{lcccccc}
\hline Dam & Period $(\mathrm{s})$ & Rock type & SLO $a(\widetilde{T})\left(\mathrm{m} / \mathrm{s}^{2}\right)$ & SLD $a(\widetilde{T})\left(\mathrm{m} / \mathrm{s}^{2}\right)$ & $\operatorname{SLV} a(\widetilde{T})\left(\mathrm{m} / \mathrm{s}^{2}\right)$ & $\operatorname{SLC} a(\widetilde{T})\left(\mathrm{m} / \mathrm{s}^{2}\right)$ \\
\hline 2 & 0.23 & granite & 1.9 & 2.31 & 5.22 & 6.46 \\
3 & 0.3 & & 1.07 & 1.5 & 4.72 & 6.12 \\
4 & 0.33 & & 1.53 & 2 & 5.4 & 7.3 \\
\hline
\end{tabular}

displacement and the yielding displacement at dam top. The analysis showed that plastic displacement happens in downstream direction only, and plastic displacement can only be added in that direction: therefore, the maximum plastic displacement coincides with residual displacement. In particular, at the end of the earthquake, dam top displacement coincides with dam base displacement and represents the residual displacement, since the dam body is considered as linear elastic. Base residual displacement can be valued in terms of ductility factor as

$$
y_{R}=y_{\max }-y_{y}=y_{y}(\mu-1) .
$$

Once knowing the yielding displacement, $y_{y}$ evaluated as

$$
y_{y}=p \cdot D_{y}=p \cdot \frac{\widetilde{R}_{y}}{K} .
$$

In the following, results obtained for several earthquakes are reported in graphs $\beta-\mu$.

4.2. Critical Acceleration: Influence of Main Parameters. Before discussing the results of nonlinear dynamic analysis, it is worth making some remarks on the role of relevant variable parameters such as dam height and foundation rock resistance, whose variation modifies dam seismic response. An indicative estimate of the results can be achieved by observing the development of the limit response acceleration (defined in (16)) versus dam height considering the three different foundation rock types. If the system is subjected to acceleration time history with elastic peak response greater than $a_{L}$, the sliding resistance of the foundation rock is attained and the system exhibits nonlinear response.

It is interesting to observe how the limit acceleration $a_{L}$ varies depending on the foundation rock type (granite, limestone-dolomite, sandstone) and the dam height $L$.

Results are shown in Figure 3 where $a_{L}$ is represented as a function of the height for the three rock types, in case of normal flood level, representing the normal functioning condition of the reservoir. Let us consider at first the smaller dam $L=42.1 \mathrm{~m}$ and observe the limit acceleration dependence on the foundation resistance. In this case, the maximum limit acceleration is obtained for the sandstone rock $\left(c=180 \mathrm{kPa}, \phi=29^{\circ}\right)$, whereas the minimum value is achieved for the granite $\left(c=50 \mathrm{kPa}, \phi=35^{\circ}\right)$. In this situation, depending on the dam geometry, uplift pressures, and passive wedge resistance, the cohesive component prevails on the frictional component on the computation of the total sliding foundation resistance. The same trend is seen by varying the dam height. However, when increasing it, the difference of limit acceleration obtained for the three materials diminishes. It can be noticed that, the values of the limit acceleration usually decrease at greater heights and that such trend is generally observed regardless of the foundation rock type. In the range considered, as dam height increases, the structure becomes more vulnerable to seismic action since limit acceleration decreases. As a consequence, the possibility of occurring plastic displacement due to the sliding of foundation is higher. In the most critical case, the value of the limit acceleration is in the range of $2 \leq a_{L} \leq$ $4 \mathrm{~m} / \mathrm{s}^{2}$. The effect of a reduction of the impounded water level to $L_{w} / L=0.85$ can be seen in Figure 4. Comparing with Figure 3, here where the limit acceleration versus dam height for the three rock types is reported, one can see that, as expected, the limit acceleration increases with respect to normal flood level and the improvement is greater as the dam height increases.

The influence of rock type on resistance hierarchy is the same regardless of the water level. However, the increase of limit acceleration varies from rock to rock and is greater for sandstone. In the most critical case, the value of the limit acceleration is in the range of $4.5 \leq a_{L} \leq 8.5 \mathrm{~m} / \mathrm{s}^{2}$ by considering the three rocks.

The effects of other water levels are shown in Figure 5, as an example, for the case of Dam $3(L=86.8 \mathrm{~m})$ on granite rock, where the development of limit response acceleration versus water level to dam height ratio is shown. The range considered is from full reservoir to half impounded reservoir $\left(L_{w} / L=0.5-1\right)$. The limit acceleration increases more than linearly as water level ratio decreases. Water level reduction reduced horizontal water pressure, uplift pressure, and added mass. The dependence appears regular in the range examined. 
TABLe 9: New dams: values of $\beta$ for each dam type evaluated with the spectral acceleration of Table 7 with reference to SLV, SLC, and an action with return period of $T_{\mathrm{RET}}=475$ years, for granite (case of normal flood and case with $L_{w} / L=0.85$ ).

\begin{tabular}{|c|c|c|c|c|c|c|c|}
\hline \multirow{2}{*}{ Dam tag } & \multirow{2}{*}{ Rock type } & \multicolumn{3}{|c|}{ normal flood } & \multicolumn{3}{|c|}{$L_{w} / L=0.85$} \\
\hline & & $\operatorname{SLV} \beta$ & $\operatorname{SLC} \beta$ & $\mathrm{SL}_{475} \beta$ & $\operatorname{SLV} \beta$ & $\operatorname{SLC} \beta$ & $\mathrm{SL}_{475} \beta$ \\
\hline 2 & granite & 0.44 & 0.40 & 0.68 & 0.83 & 0.77 & $>1$ \\
\hline 3 & & 0.36 & 0.33 & 0.61 & 0.77 & 0.7 & $>1$ \\
\hline 4 & & 0.28 & 0.25 & 0.50 & 0.61 & 0.55 & $>1$ \\
\hline
\end{tabular}

TABLE 10: Existing dams: values of $\beta$ for each dam type evaluated with the spectral acceleration of Table 8 with reference to SLV, SLC, for granite (case of normal flood and case with $L_{w} / L=0.85$ ).

\begin{tabular}{|c|c|c|c|c|c|}
\hline \multirow{2}{*}{ Dam tag } & \multirow{2}{*}{ Rock type } & \multicolumn{2}{|c|}{ normal flood } & \multicolumn{2}{|c|}{$L_{w} / L=0.85$} \\
\hline & & $\operatorname{SLV} \beta$ & $\operatorname{SLC} \beta$ & $\operatorname{SLV} \beta$ & $\operatorname{SLC} \beta$ \\
\hline 2 & granite & 0.53 & 0.43 & $>1$ & 0.83 \\
\hline 3 & & 0.50 & 0.36 & $>1$ & 0.77 \\
\hline 4 & & 0.36 & 0.26 & 0.8 & 0.6 \\
\hline
\end{tabular}

\section{Seismic Analysis: Discussion of Results}

Dynamic analyses with the simplified model are carried out on the four examples of dams in case of normal flood level. The objective is to evaluate dam response in terms of displacements, as a function of the seismic action and the sliding foundation resistance. In the following, the results of the analysis are plotted on graphs where the ductility factor $\mu$ is function of the acceleration ratio $\beta$. Then, in order to obtain the real dam residual displacement $y_{R}$ for a given $\beta$, (19) must be applied once known $\mu$ and the yielding displacement $y_{y}$. Cases relative to each foundation rock will be presented for the four dams considered. Results concerning granite, limestone-dolomite, and sandstone rock are given in Figures 6, 7, and 8, respectively.

The number of seismic events for which residual displacement occurs depends on the dam height and on the foundation rock. The greatest number is obtained for Dam 4, which is the highest dam $(L=95.5 \mathrm{~m})$ in case of less resistant foundation rock, Figure 6 (the granite case already shown in Figure 3). The smallest number corresponds to the lowest Dam 1, $L=42.1 \mathrm{~m}$ on stronger foundation, sandstone, Figure 8. Obviously, as the foundation rock resistance increases (increasing $a_{L}$ ) the number of seismic events for which residual displacement occurs decreases: in fact, in the case of sandstone (which corresponds to the best rock considered), the lower dams (Dams 1 and 2) plasticize for two events only.

The behavior of $\mu$ versus $\beta$ shows a similar trend for the three different foundations; for this reason, results reported separately in Figures 6-8 are then plotted together for all rock types: Figure 9. It can be observed that, since $\beta$ is in the range $0.5-1$, results show a similar and regular trend, which can be easily interpolated. In the region where strong nonlinear behavior is attended, $\beta<0.5$, results are instead disperse with high ductility values, that is, high residual displacements. By focusing attention on the region $0.5<\beta<1$, on the basis of the results obtained, the ductility factor can be expressed as a function of $\beta$ by interpolating results in this region and rounding them up. In the range of $0.5<\beta<1$, a curve, which fits data with only one case in which is overtaken, is

$$
\mu=\frac{1}{\beta} .
$$

The expression reported in (21) is represented with a solid line in Figure 10. For values of the acceleration ratio lower than $\beta=0.5$, the estimation of residual displacement requires the numerical evaluation case by case, and a more accurate structural model should be utilized.

Summing up, a guess of the residual displacement can be easily obtained without performing nonlinear analysis if expression (21) is utilized in case $\beta \geq 0.5$. The simplified procedure requires the definition of an equivalent nonlinear SDOF system (defining dam-reservoir-foundation characteristics), whereas the seismic input parameter is the elastic spectral acceleration.

The main steps of the procedure are reported in the following:

(1) define the dam geometry, the water level in the reservoir, and the foundation rock type and evaluate the equivalent parameters of the SDOF system, Table 4;

(2) evaluate the limit response acceleration with (16);

(3) depending on dam location, define the value of the attended spectral acceleration relative to the period of the equivalent SDOF system;

(4) define $\beta$ as the ratio between limit response acceleration and spectral acceleration;

(5) if $\beta \geq 1$, the dam is safe against sliding of foundation and no residual displacement occurs; if $\beta<1$ go to the next step;

(6) if $0.5 \leq \beta \leq 1$, valuate the expected ductility $\mu$ by using (21);

(7) evaluate the yielding displacement of the equivalent SDOF system $y_{y}$ with (20); 
TABLE 11: New dams: values of $y_{R}(\mathrm{~mm})$ for each dam type evaluated with the spectral acceleration of Table 7 with reference to SLV, SLC, and an action with return period of $T_{\mathrm{RET}}=475$ years, for granite (n.c.: not calculated, - : no residual displacement) (case of normal flood and case with $\left.L_{w} / L=0.85\right)$.

\begin{tabular}{lcccccc}
\hline \multirow{2}{*}{ Dam tag } & \multirow{2}{*}{ Rock type } & Normal flood & \multicolumn{2}{c}{$L_{w} / L=0.85$} \\
SLV $y_{R}$ & SLC $y_{R}$ & SL $_{475} y_{R}$ & SLV $y_{R}$ & SL $_{475} y_{R}$ \\
\hline 2 & granite & n.c. & n.c. & 17 & 8 & 11 \\
3 & & n.c. & n.c. & 40 & 19 & 28 \\
4 & & n.c. & n.c. & 80 & 45 & 58 \\
\hline
\end{tabular}

TABle 12: Existing dams: values of $y_{R}(\mathrm{~mm})$ for each dam type evaluated with the spectral acceleration of Table 8 with reference to SLV, SLC, for granite (n.c.: not calculated, - : no residual displacement) (case of normal flood and case with $L_{w} / L=0.85$ ).

\begin{tabular}{lccccc}
\hline \multirow{2}{*}{ Dam tag } & \multirow{2}{*}{ Rock type } & \multicolumn{2}{c}{ Normal flood } & \multicolumn{2}{c}{$L_{w} / L=0.85$} \\
& & SLV $y_{R}$ & SLC $y_{R}$ & SLV $y_{R}$ & SLC $y_{R}$ \\
\hline 2 & granite & 21 & n.c. & - & 8 \\
3 & & 73 & n.c. & - & 21 \\
4 & & n.c. & n.c. & 18 & 47 \\
\hline
\end{tabular}

(8) evaluate the expected residual displacement $y_{R}$ with (19);

(9) if $\beta<0.5$, conduct specific seismic analysis with a more refined structural model; however, a large residual displacement is expected.

Residual displacement generally depends on

(i) dam height: it increases by increasing $L$;

(ii) $\beta$ value: it increases by decreasing the sliding foundation resistance, by increasing the seismic action, and, finally, by increasing the water level in the reservoir.

In the next section, the simplified procedure here exposed is applied to estimate residual displacement for three of the four dams with reference to the elastic response spectra furnished by the Italian Code for different return periods.

\section{Examples of Applications}

The above methodology, illustrated with a simplified model, can be conveniently utilized to preliminary evaluate seismic safety of concrete gravity dams against sliding of the foundation without performing nonlinear step by step dynamic analysis. In this study, the procedure is applied for concrete gravity dams with seismic action defined by the Italian Code in terms of elastic response spectra, site by site, and on a very dense discretization.

The proposed approach follows the prescription of Italian Code to evaluate seismic response. Dynamic effect of impounded water is taken into consideration. At least, the Italian Code requires, in case of dynamic analysis, to consider an added mass; according to it, hydrodynamic pressure on the dam upstream face can be obtained disregarding dam deformability and dam-foundation interaction just applying Westergaard theory. In the present study the supplementary mass is obtained based on a more sophisticated expression, which takes into consideration the rigid motion of the base and the relative motion of the dam due to its flexibility as well as dam-foundation interaction. For the other aspects, the analysis followed the indications given by the Code.

Elastic response spectra furnished by the Italian Code, refer to rock, indicated as soil $\mathrm{A}$; the action varies in relation to the seismicity of the zone where dams are located and is differently defined for new or existing dams. A factor of $5 \%$ it is conventionally assumed as structural damping. Seismic action is defined in Italy for all country sites at a net of about 5 by $5 \mathrm{~km}$, at different return periods. For each site spectrum, four different mean return periods are given since the Italian Code highlights four limit states, related to different probability levels of occurrence of the seismic event. They are indicated as follows:

SLO: which is related to the condition of surpassing the dam normal functioning,

SLD: which is related to the condition of moving from reversible to irreversible disservice,

SLV: which is related to a disservice that can cause human loss,

SLC: which is related to structure collapse or uncontrolled water release.

The first two refer to serviceability limit states, whereas the last two refer to ultimate limit states.

According to the draft version of the Technical Code for dams design and construction (27-03-2008), dams are classified depending on their dimensions and importance and can be divided in strategic or not strategic structures. In the following, the dams examined are considered as strategic structures. Depending on whether dam is classified as new or existing, the Italian Code defines different design return periods for each limit state. Both cases are considered. The reference life (in years) is valued as

$$
V_{R}=V_{N} C_{U}
$$

where $V_{N}$ is the nominal life ( $V_{N}=100$ for new dams, $V_{N}=$ 50 for existing dams) and $C_{U}$ the importance coefficient $\left(C_{U}=2\right)$. Summarizing, reference life for new and existing dams is 200 and 100 years, respectively. On the basis of such values, the four return periods $T_{\mathrm{RET}}$, taken from the Technical Code, related to the limit state considered, with the probability of occurrence $P_{V R}$, are reported in Table 5 .

In the following, Dam 1 will not be taken into account, since it is considered to be located in a nonseismic region. 
As an example, the elastic response spectra for the site of Dam 2 are reported in Figure 11 in the case of new dam. The elastic response spectra for the same dam considered as existing have the same shape but lower level of spectral acceleration.

In Table 6, the peak ground acceleration for the three sites examined with reference to an action having a return period of $T_{\mathrm{RET}}=475$ years is reported as well.

For the sake of exemplification, in order to illustrate the procedure, let us assume for each dam the foundation rock type granite (which is the less resistant among the three previously considered). It is useful to remark that the examples treated correspond to real cases as regards dam geometry and seismic action used, but not as regards foundation rock resistance which, in these examples, always constitutes a variable and here is treated as a parameter. For this reason, residual displacement obtained for the three dams considered does not correspond to the real case. The yielding displacement $y_{y}$ is $36 \mathrm{~mm}, 62 \mathrm{~mm}$, and $68 \mathrm{~mm}$, for dam 2, 3, and 4, respectively. Once knowing the equivalent fundamental period and the total mass of the system (Table 4), it is possible to evaluate the corresponding spectral acceleration for each limit state by using the response spectra furnished by the code. Results in terms of spectral acceleration are reported in Tables 7 and 8 for new and existing dams, respectively. For comparison purposes, the case of an action with return period of $T_{\mathrm{RET}}=475$ years is reported as well. Among the dams considered, dam 2 has the strongest seismic action. $\beta$ is estimated once knowing the limit acceleration of each dam (Figure 3 ) which is, in case of granite rock and normal flood level, $a_{L}=2.80,2.2,1.93 \mathrm{~m} / \mathrm{s}^{2}$ for dams $2,3,4$, respectively. $\beta$ values relative to condition of normal flood level are given in Tables 9 and 10 for new and existing dams, respectively. The attention is focused on the ultimate state conditions only (SLV, SLC — which are the worst situations) and on an action with return period of 475 years.

For new dams, since design spectral accelerations are greater than for existing dams, the attained $\beta$ values are generally lower. In case of new dams, residual displacement will occur for both ultimate limit states (in fact it is always $\beta<1)$. Although it is obvious that $\beta$ value in the SLV is lower than in SLC, however, for the three dams, $\beta$ values are always small, indicating strong nonlinear behavior and considerable displacement. The accurate evaluation of residual displacement in the cases with $\beta$ smaller than 0.5 should be considered with a more refined nonlinear dynamic analysis. For these cases, residual displacement is not estimated with the simplified procedure. By the way, greater residual displacement will occur in the latter case (SLC). In case of existing dams, the simplified procedure can be applied in most cases $(\beta>0.5)$. Residual displacement can be estimated with the simplified procedure for Dams 2 and 3 only with reference to the ultimate limit state SLV. With the seismic action corresponding to a return period of 475 years, $\beta$ is always greater or equal to 0.5 ; therefore, the simplified procedure could be always applied. By evaluating the ductility factor with (21) and knowing the yielding displacement for each dam, the residual displacement is estimated with (19) and it is reported for the cases where the simplified procedure is applicable in Tables 11 and 12 for new and existing dams, respectively, with reference to normal flood level.

For new dams, the simplified procedure can be applied with reference to an action with $T_{\mathrm{RET}}=475$ years. Expected residual displacement ranges from a minimum value of $17 \mathrm{~mm}$ for Dam 2 to a maximum value of $80 \mathrm{~mm}$ for Dam 4 , the highest. In case of existing dams, as expected, obtained permanent displacements are lower. Residual displacement can be estimated with the simplified procedure for Dams 2 and 3 only. For SLV, the values are 21 and $73 \mathrm{~mm}$, respectively.

From the examined examples, it appears that the simplified procedure is applicable to a moderate number of cases, in particular for existing dams, where seismic actions to be considered are smaller. Therefore, it is expected that a rapid screening of existing gravity dams is feasible with this procedure. It is possible to prevent earthquake-induced damage by reducing the water level in the reservoir essentially for the increase of critical acceleration, as discussed in the previous sections. The dynamic response of the dam is reduced as well, essentially due to a reduction of the equivalent mass of the system. As proof of the benefits obtained by the structure from the reduction of the water level in the reservoir, residual displacement in case of water level ratio $L_{w} / L=0.85$ is also estimated for the three dams considered and is to be compared with the situation of normal flood level.

The limit acceleration of each dam in case of water level ratio of $L_{w} / L=0.85$ (Figure 4 ) for granite rock is $a_{L}=5.38,4.71,4.33 \mathrm{~m} / \mathrm{s}^{2}$ for Dams 2, 3, 4, respectively; the yielding displacement $y_{y}$ is $37 \mathrm{~mm}, 65 \mathrm{~mm}$, and $71 \mathrm{~mm}$, for dams 2, 3, and 4, respectively. $\beta$ values are reported in Tables 9 and 10: they are relative to water level ratio of $L_{w} / L=0.85$ for new and existing dams, respectively, in the ultimate state condition (SLV, SLC) and for an action with a return period of 475 years. As expected, $\beta$ values reduce with respect to normal flood condition, due to the increase of limit acceleration $a_{L}$. Obtained $\beta$ are always greater than 0.5 (Tables 9 and 10); by the way the simplified procedure is always applicable to estimate base sliding. Residual displacement is estimated with the simplified procedure, and results are reported in Tables 11 and 12 for new and existing dams, respectively, with reference to water level ratio of $L_{w} / L=0.85$. Residual displacements are attended for both new and existing dams. The worst situation in terms of plastic displacement is always observed for Dam 4, the highest one, as well as for new dam which can attain maximum residual displacement equal to $58 \mathrm{~mm}$, for limit state SLC. In case of new dams, obtained $\beta$ with water level reduced are generally double with respect to normal flood level situation. In case of sandstone rock, residual displacement will not be attained. For a seismic action having a return period of 475 years, none of the three dams attains plastic response. In case of existing dams, only Dam 4 attains very small permanent displacement for limit state SLV, whereas very small base sliding is observed in case SLC for the three dams. 
The example considered confirms that even a small reduction in water level gives a large safety increase with a strong reduction of possible permanent displacement. The proposed method becomes usually applicable for water level reduction.

\section{Comparisons with Results in Chopra and Zhang [10]}

A comparison of the present paper with the one by Chopra and Zhang [10] (that focuses, by means of a simplified model, on the relevant aspects influencing dam base sliding), seems to be useful, for completing the dissertation and concluding with general recommendations.

The work by Chopra and Zhang treated the problem of earthquake-induced base sliding of concrete gravity dams by means of a simplified model. Dam had been modeled at first as rigid and then as flexible, by approximating dam motion with the first mode shape. The hydrodynamic effect of the water in the reservoir had been included first considering the contribution of the acting hydrodynamic pressure due to acceleration of rigid dam only (Westergaard solution) and then also considering dam acceleration due to its flexibility. Structure-foundation interaction has not been considered. The effect of a different rock resistance has been indirectly counted by varying friction coefficient. The analyses were carried out with a step by step procedure considering few natural earthquakes only, and the dependence of the residual displacement on some relevant parameters (such as dam height and elastic modulus, water level, friction coefficient, and downstream face slope) has been outlined. The main results obtained are summarized in the following. Dam tends to slide only in downstream direction because limit acceleration is much smaller compared with case of upstream sliding. Permanent displacement increases with higher intensity of ground shaking and is greater for systems with smaller limit acceleration, which results from a smaller friction coefficient, steeper slope of downstream face, increasing depth of impounded water, or increasing uplift force. Comparing results of modeling the dam as rigid or flexible showed that flexibility had the effect of increasing permanent displacement. This is due to dynamic amplification of response. Concerning the model for hydrodynamic pressures, results showed that considering the effect of the rigid body motion only (Westergaard solution), in comparison with the case where also dam flexibility is included, provides the order of magnitude of the sliding displacement, which is a conservative value for most cases when this displacement may be practically significant. Namely, in presence of large permanent displacements, disregarding hydrodynamic term due to dam flexibility leads to conservative results.

The novelties introduced by our study mainly regard modeling structure foundation interaction with a non linear law. The sliding resistance has been represented by a cohesive and an attritive part and the beneficial effect of the presence of a passive wedge resistance has been also taken into account. The effect of the variation of foundation characteristics on dam response in terms of base sliding has been highlighted. Step by step analyses have been carried out on a large number of earthquakes in order to have a wider statistics. At the end, a simplified and general procedure has been given to attain possible residual displacement without performing nonlinear analysis. A recommendation, which was not asserted in this study although it is valid in this context too, can be extended here as conclusion, being also useful to give support to the Italian Code prescriptions. It refers to the problem of modeling the hydrodynamic pressures. It seems that using the approximation of rigid body motion to evaluate the hydrodynamic component instead of using also the term due to dam flexibility, leads to results which are generally conservative in terms of residual displacements. Such assumption is valid with reference to relative strong motion which corresponds to the most interesting cases when sliding displacement becomes significant.

\section{Conclusion}

In this study, the evaluation of possible residual displacement on concrete gravity dams produced by an earthquake has been carried out by using a simplified mechanical model. The model, originally proposed by Fenves and Chopra for linear analysis, is a single-degree-of-freedom system where the dam is assumed to remain elastic and it takes into account the most relevant parameters influencing seismic response which are dam-water and dam-foundation interaction. Here the model has been enriched including nonlinearity in the substructure to catch base sliding, given a threshold value for the sliding foundation resistance modeled with the Mohr-Coulomb criterion, including a frictional and a cohesive component. The hydrodynamic effects of the water in the reservoir are modeled by means of a supplementary mass damping and force, and the effect of the presence of a passive wedge resistance has been included as well. 36 natural earthquakes registered in the Italian country, and 10 earthquakes taken from the PEER and ESD database have been utilized as input time history. As real case studies, seismic analyses have been carried out on four typical examples of Italian concrete gravity dams, of different heights and with normal flood level in the reservoir, whereas three types of foundation rock have been hypothesized. The utilized values refer to real data which are representative of typical foundation rocks. Results are reported in graphs where the ductility factor $\mu$, that is, the ratio between total displacement and displacement at incipient sliding, is expressed as a function of the acceleration ratio $\beta$, defined as the ratio between the limit response acceleration at incipient sliding and the spectral acceleration at natural period of the dam with very small dispersion when $\beta>0.5$. It has been noticed that the trend can be well represented by a simple analytical law if the value of the acceleration ratio $\beta$ is not lower than 0.5. On the basis of the obtained results a simplified methodology for a preliminary evaluation of residual displacement has been set up, validated, and applied. Dam seismic residual displacement can be estimated without 
performing nonlinear dynamic analysis, once evaluating the equivalent SDOF system parameters. These depend on dam height, impounded water level, and foundation rock type. Given the fact that the dispersion in response is very small for a given $\beta$ when this parameter is larger than 0.5 , it seems sufficient to consider the response spectrum as seismic input. The proposed methodology has been illustrated with reference to seismic response spectra given site by site by the Italian Code for different return periods corresponding to the different limit states to be checked. Residual displacement with reference to both cases of new and existing dams has been obtained, for each dam located in a different site, for a particular type of foundation rock. As expected, obtained residual displacements for existing dams are lower with respect to those of new dams because the seismic action is less severe. Depending on foundation rock and dam height, residual displacement may reasonably vary. For comparison purposes, the analysis was repeated for a reduced water level in the reservoir $\left(L_{w} / L=0.85\right)$ to underline the benefits obtained on dam response in terms of base sliding as a possible safety measure against seismic action. In some cases, the structure was shown to remain in the elastic field with no residual displacement and, in the other cases considered, the simplified procedure was always applicable when $\beta$ was larger than 0.5 .

In conclusion, if $\beta$ is larger than 0.5 , residual displacement can be valued with adequate reliability and the residual displacement values are small. The simplified method represents a useful tool for the quick screening of dams. If one can assume to accept this residual displacement without negative consequences for dam performances, then, one may assume that seismic response of the superstructure can be reduced of the ratio $1 / \beta$ with respect to the elastic one, that is, if $\beta=0.5$ then by 2 . However, further considerations for possible overstrength are needed.

\section{References}

[1] R. Tinawi, P. Léger, M. Leclerc, and G. Cipolla, "Seismic safety of gravity dams: from shake table experiments to numerical analyses," Journal of Structural Engineering, vol. 126, no. 4, pp. 518-529, 2000.

[2] J. W. Chavez and G. L. Fenves, "Earthquake response of concrete gravity dams including base sliding," Journal of Structural Engineering, vol. 121, no. 5, pp. 865-875, 1995.

[3] R. A. Mir and C. A. Taylor, "An investigation into the base sliding response of rigid concrete gravity dams to dynamic loading," Earthquake Engineering and Structural Dynamics, vol. 25, no. 1, pp. 79-98, 1996.

[4] A. K. Chopra, "Earthquake analysis of arch dams: factors to be considered," in Proceedings of the 14th World Conference on Earthquake Engineering, Benijing, China, October 2008.

[5] M. B. Ftima and P. Léger, "Seismic stability of cracked concrete dams using rigid block models," Computers and Structures, vol. 84, no. 28, pp. 1802-1814, 2006.

[6] O. A. Pekau and X. Zhu, "Seismic behaviour of cracked concrete gravity dams," Earthquake Engineering and Structural Dynamics, vol. 35, no. 4, pp. 477-495, 2006.

[7] Y. Calayir and M. Karaton, "Seismic fracture analysis of concrete gravity dams including dam-reservoir interaction,"
Computers and Structures, vol. 83, no. 19-20, pp. 1595-1606, 2005.

[8] M. Ghaemian and A. Ghobarah, "Nonlinear seismic response of concrete gravity dams with dam-reservoir interaction," Engineering Structures, vol. 21, no. 4, pp. 306-315, 1999.

[9] C. Zhao, T. P. Xu, and S. Valliappan, "Seismic response of concrete gravity dams including water-dam-sedimentfoundation interaction," Computers and Structures, vol. 54, no. 4, pp. 705-715, 1995.

[10] A. K. Chopra and L. Zhang, "Earthquake-induced base sliding of concrete gravity dams," Journal of Structural Engineering, vol. 117, no. 12, pp. 3698-3719, 1991.

[11] A. Danay and L. N. Adeghe, "Seismic-induced slip of concrete gravity dams," Journal of Structural Engineering, vol. 119, no. 1, pp. 108-129, 1993.

[12] M. Basili and C. Nuti, "Seismic simulation and base sliding of conctrete gravity dams," in Computational Methods in Earthquake Engineering, M. Papadrakakis, M. Fragiadakis, and N. D. Lagaros, Eds., vol. 21, pp. 427-454, Springer, 2010.

[13] G. Fenves and A. K. Chopra, "Simplified earthquake analysis of concrete gravity dams," Journal of Structural Engineering, vol. 113, no. 8, pp. 1688-1708, 1987.

[14] C. Nuti and C. E. Pinto, "Analisi dell'interazione terreno struttura in condizioni sismiche," in Interazione TerrenoStruttura in Prospettiva Sismica, M. Mele, Ed., CISM-Collana di Ingegneria Strutturale n. 6, CISM, 1990.

[15] G. Scasserra, J. P. Stewart, R. E. Kayen, and G. Lanzo, "Database for earthquake strong motion studies in Italy," Journal of Earthquake Engineering, vol. 13, no. 6, pp. 852-881, 2009.

[16] "Peer Strong Motion Database," http://peer.berkeley.edu/ smcat/.

[17] "European Strong Motion Database," http://www.isesd.hi.is/ ESD_Local/frameset.htm.

[18] N. Shome, C. A. Cornell, P. Bazzurro, and J. E. Carballo, "Earthquakes, records, and nonlinear responses," Earthquake Spectra, vol. 14, no. 3, pp. 469-500, 1998. 

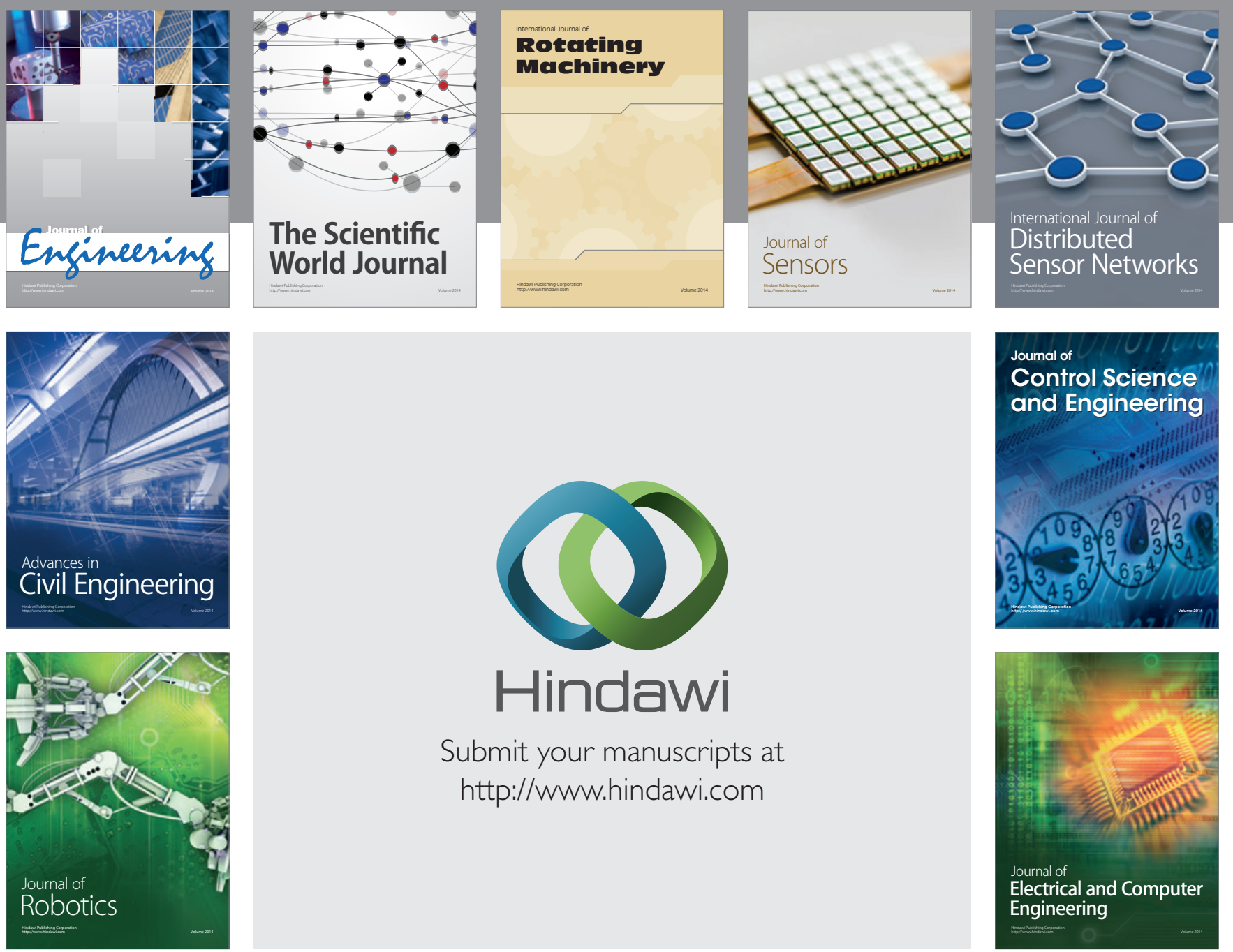

Submit your manuscripts at

http://www.hindawi.com
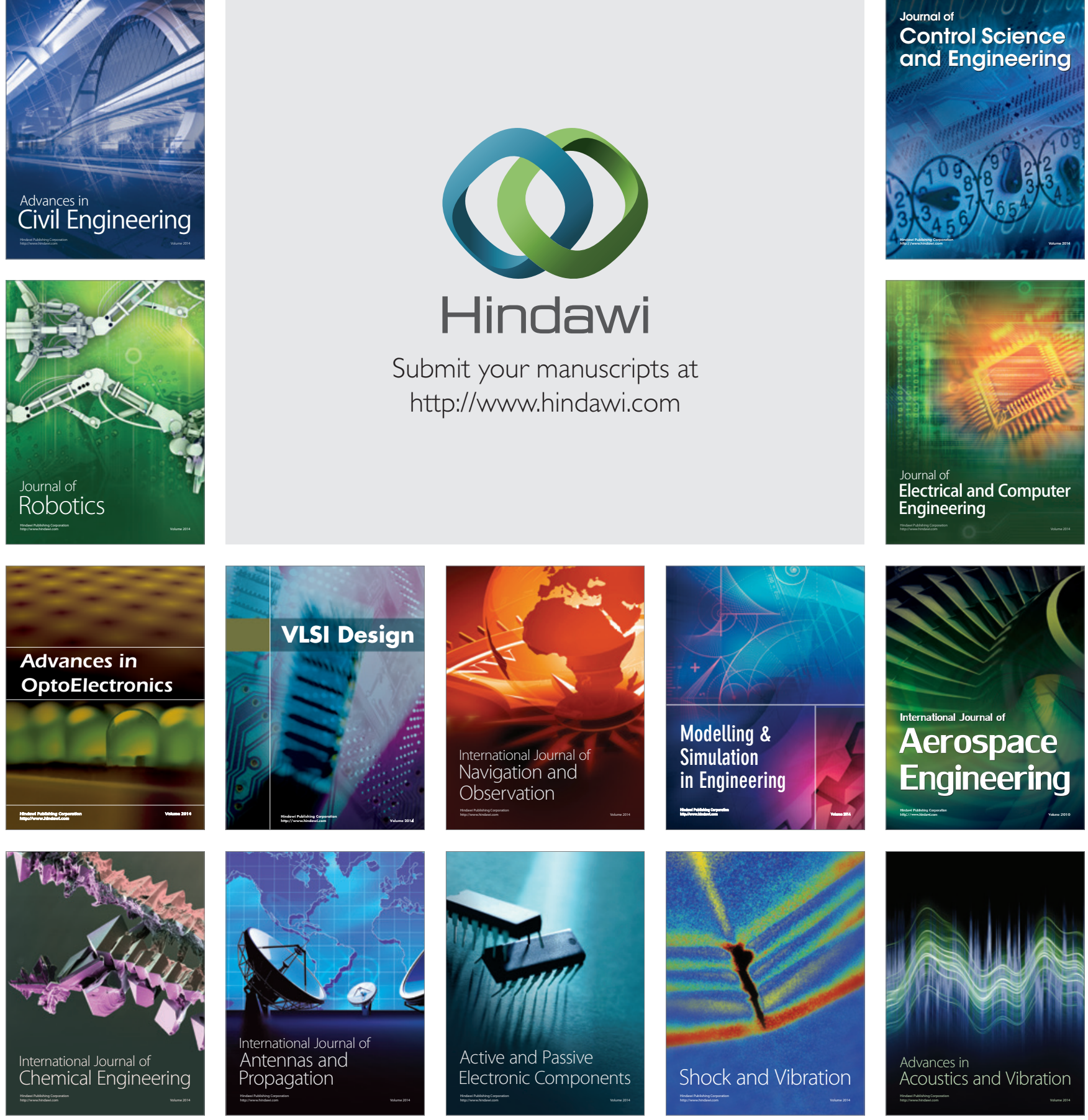